\title{
Invention of the plane geometrical formulae - Part II
}

\author{
Mr. Satish M. Kaple \\ Asst. Teacher Mahatma Phule High School, Kherda Jalgaon (Jamod) - 443402 Dist- Buldana, Maharashtra (India)
}

Abstract: In this paper, I have invented the formulae for finding the area of an Isosceles triangle. My finding is based on pythagoras theorem.

\section{Introduction}

A mathematician called Heron invented the formula for finding the area of a triangle, when all the three sides are known. Similarly, when the base and the height are given, then we can find out the area of a triangle. When one angle of a triangle is a right angle, then we can also find out the area of a right angled triangle. Hence forth, We can find out the area of an equilateral triangle by using the formula of an equilateral triangle. These some formulae for finding the areas of a triangles are not exist only but including in educational curriculum also.

But, In educational curriculum. I don't appeared the formula for finding the area of an isosceles triangle with doing teaching - learning process . Hence, I have invented the new formula for finding the area of an isosceles triangle by using Pythagoras theorem.

I used pythagoras theorem with geometrical figures and algebric equations for the invention of the new formula of the area of an isosceles triangle. I Proved it by using geometrical formulae \& figures, 20 examples and 20 verifications (proofs).

Here myself is giving you the summary of the research of the plane geometrical formulae- Part II

\section{Method}

First taking an isosceles triangle $\mathrm{ABC}$

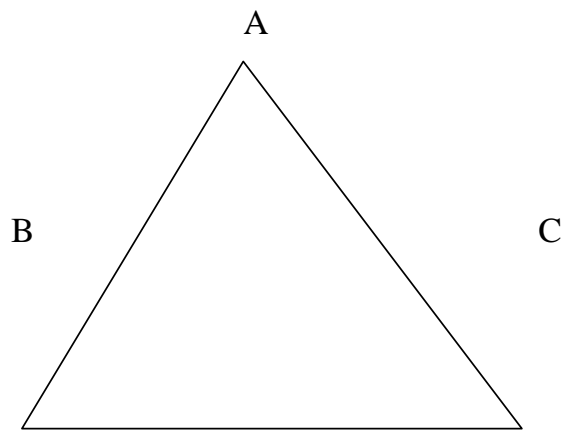

Now taking $\mathrm{a}, \mathrm{a} \& \mathrm{~b}$ for the lengths of three sides of $\triangle \mathrm{ABC}$

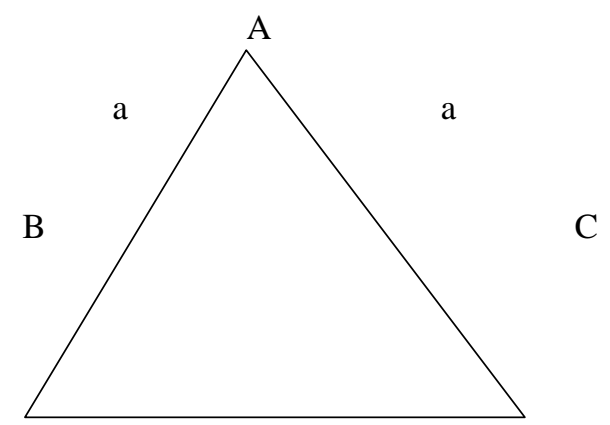


Draw perpendicular $\mathrm{AD}$ on $\mathrm{BC}$.

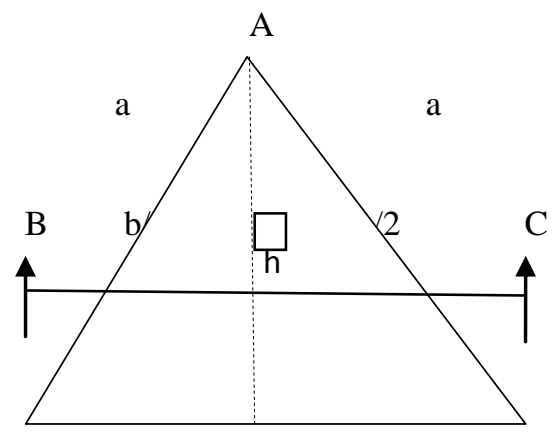

$\triangle \mathrm{ABC}$ is an isosceles triangle and it is an acute angle also.

In $\triangle \mathrm{ABC}$,

Let us represent the lengths of the sides of a triangle with the letters a,a,b. Side $\mathrm{AB}$ and side $\mathrm{AC}$ are congruent side.

Third side $\mathrm{BC}$ is the base. $\mathrm{AD}$ is perpendicular to $\mathrm{BC}$.

Hence, $\mathrm{BC}$ is the base and $\mathrm{AD}$ is the height.

Here, taking $\mathrm{AB}=\mathrm{AC}=\mathrm{a}$

Base, $\mathrm{BC}=\mathrm{b}$ Height, $\mathrm{AD}=\mathrm{h}$

In $\triangle \mathrm{ABC}$, two congruent right angled triangle are also formed by the length of perpendicular $\mathrm{AD}$ drawn on the side $\mathrm{BC}$ from the vertex $\mathrm{A}$. By the length of perpendicular $\mathrm{AD}$ drawn on the side $\mathrm{BC}$, Side $\mathrm{BC}$ is divided into two equal parts of segment. Therefore, these two equal segments are seg DB and seg DC. Similarly, two a right angled triangles are also formed, namely, $\triangle \mathrm{ADB}$ and $\triangle \mathrm{ADC}$ which are congruent.

Thus,

$\mathrm{DB}=\mathrm{DC}=1 / 2 \times \mathrm{BC}$

$\mathrm{DB}=\mathrm{DC}=1 / 2 \times \mathrm{b}=\mathrm{b} / 2$

$\triangle \mathrm{ADB}$ and $\triangle \mathrm{ADC}$ are two congruent right angled triangle.

Taking first right angled $\triangle \mathrm{ADC}$,

In $\triangle \mathrm{ADC}, \quad$ Seg $\mathrm{AD}$ and Seg $\mathrm{DC}$ are both sides forming

the right angle. Seg $\mathrm{AC}$ is the hypotenuse.

Here, $\quad \mathrm{AC}=\mathrm{a}$

Height , $\mathrm{AD}=\mathrm{h}$

$\mathrm{DC}=\mathrm{b} / 2$ and $\mathrm{m} \angle \mathrm{ADC}=90^{\circ}$

According to Pythagoras Theorem,

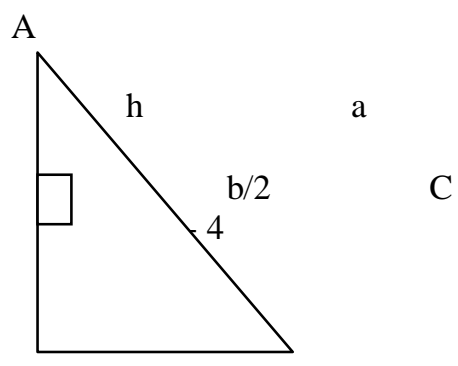

(hypotenuse $)^{2}=(\text { one side forming the right angle })^{2}+(\text { second side forming the right angle })^{2}$

In short,

$(\text { Hypotenuse })^{2}=(\text { one side })^{2}+(\text { second side })^{2}$

$$
\begin{gathered}
A C^{2}=A D^{2}+D^{2} \\
A D^{2}+D C^{2}=A C^{2} \\
h^{2}+(b / 2)^{2}=a^{2} \\
h^{2}=a^{2}-(b / 2)^{2} \\
h^{2}=a^{2}-b^{2}
\end{gathered}
$$

$\mathrm{h}^{2}=\mathrm{a}^{2} \times 4-\mathrm{b}^{2}$

4

$$
\frac{4}{h^{2}}=4 a^{2}-b^{2}
$$

$\mathrm{h}^{2}=4 \mathrm{a}^{2}-\mathrm{b}^{2} \stackrel{4}{4} \quad \underline{4}$

4 
Taking the square root on both side,

$$
\begin{aligned}
\sqrt{h^{2}} & =\sqrt{\frac{4 a^{2}-}{4} b^{2}} \\
\sqrt{h^{2}} & =\sqrt{\frac{1}{4} \times\left(4 \mathrm{a}^{2}-\mathrm{b}^{2}\right)} \\
\sqrt{\mathrm{h}^{2}} & =\sqrt{\frac{4}{4} \times \sqrt{4 \mathrm{a}^{2}-b^{2}}}
\end{aligned}
$$

The square root of $h^{2}$ is $h$ and the square root of $1 / 4$ is $1 / 2$

$$
\begin{aligned}
& \therefore \mathrm{h}=1 / 2 \times \sqrt{4 \mathrm{a}^{2}-\mathrm{b}^{2}} \\
& \begin{aligned}
\therefore \text { Height, } \mathrm{h} & =1 / 2 \sqrt{4 \mathrm{a}^{2}-\mathrm{b}^{2}}
\end{aligned} \\
& \begin{aligned}
\therefore \mathrm{AD}=\mathrm{h}=1 / 2 & \sqrt{4 \mathrm{a}^{2}-\mathrm{b}^{2}} \\
\text { Thus, } & \\
\text { Area of } \triangle \mathrm{ABC} & =1 / 2 \times \text { Base } \times \text { Height } \\
& =1 / 2 \times \mathrm{BC} \times \mathrm{AD} \\
& =1 / 2 \times \mathrm{b} \times \mathrm{h}
\end{aligned}
\end{aligned}
$$

But Height, $h=1 / 2 \sqrt{4 a^{2}-b^{2}}$

$\therefore$ Area of $\triangle \mathrm{ABC}=1 / 2 \times \mathrm{b} \times 1 / 2 \sqrt{4 \mathrm{a}^{2}-\mathrm{b}^{2}}$

$$
\therefore \text { Area of } \begin{aligned}
\triangle \mathrm{ABC} & =\underset{2}{\mathrm{~b}} \times \frac{1}{2} \sqrt{4 \mathrm{a}^{2}-\mathrm{b}^{2}} \\
& =\underset{2 \times 2}{\mathrm{~b} \times 1} \times \sqrt{4 \mathrm{a}^{2}-\mathrm{b}^{2}}
\end{aligned}
$$

$$
\frac{=b}{4} \sqrt{4 a^{2}-b^{2}}
$$

$\therefore$ Area of an isosceles $\triangle \mathrm{ABC}=-\mathrm{b}_{4} \sqrt{4 \mathrm{a}^{2}-\mathrm{b}^{2}}$ 
For example- Now consider the following examples:-

Ex. (1) If the sides of an isosceles triangle are $10 \mathrm{~cm}, 10 \mathrm{~cm}$ and $16 \mathrm{~cm}$.

Find it's area

$\triangle \mathrm{DEF}$ is an isosceles triangle.

In $\triangle \mathrm{DEF}$ given alongside,

$1(\mathrm{DE})=10 \mathrm{~cm}$.

$11(\mathrm{DF})=10 \mathrm{~cm}$.

$$
1(\mathrm{EF})=16 \mathrm{~cm}
$$

Let,

$\mathrm{a}=10 \mathrm{~cm}$

Base, $b=16 \mathrm{~cm}$.

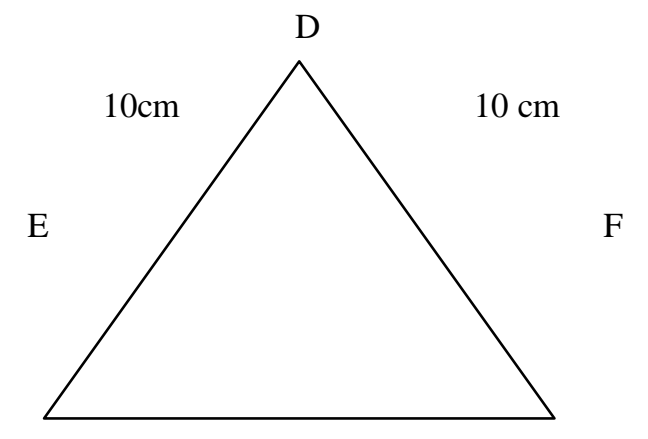

By using The New Formula of an isosceles triangle,

$\therefore$ Area of an isosceles $\triangle \mathrm{DEF}=\mathrm{A}(\triangle \mathrm{DEF})$

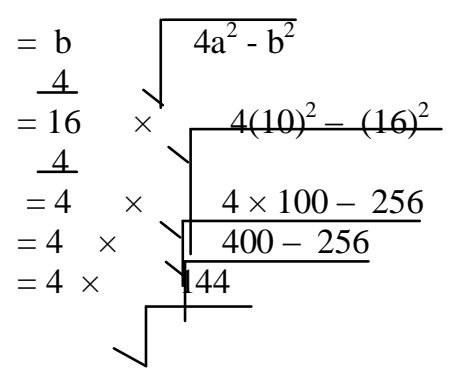

The square root of 144 is 12

$=4 \times 12=48$ sq.cm.

$\therefore$ Area of an isosceles $\triangle \mathrm{DEF}=48$ sq.cm.

\section{Verification :-}

$\rightarrow$ Here,

$$
\begin{aligned}
& 1(\mathrm{DE})=\mathrm{a}=10 \mathrm{~cm} . \\
& 1(\mathrm{EF})=\mathrm{b}=16 \mathrm{~cm} . \\
& 1(\mathrm{DF})=\mathrm{c}=10 \mathrm{~cm} .
\end{aligned}
$$

By using the formula of Heron's

Perimeter of $\triangle D E F=a+b+c$

Semiperimeter of $\triangle \mathrm{DEF}$,

$$
=10+16+10=36 \mathrm{~cm}
$$

$$
\begin{aligned}
& S=\frac{a+b+c}{2} \\
& S=\frac{36}{2} \\
& S=\frac{18 \mathrm{~cm} .}{}
\end{aligned}
$$

$\therefore$ Area of an isosceles $\triangle \mathrm{DEF}=$

$$
\begin{aligned}
& \mathrm{DEF}=\frac{\mathrm{s}(\mathrm{s}-\mathrm{a})(\mathrm{s}-\mathrm{b})(\mathrm{s}-\mathrm{c})}{=} \\
& =\sqrt{\frac{18 \times(18-10) \times(18-16) \times(18-10)}{\sqrt{18 \times 8 \times 2 \times 8}}} \\
& = \\
& =\frac{(18 \times 2) \times(8 \times 8)}{36 \times 64}
\end{aligned}
$$

The square root of 36 is 6 and the square root of 64 is 8

$\therefore$ Area of $\triangle \mathrm{DEF}=48 \mathrm{sq} . \mathrm{cm}$

$$
=6 \times 8=48 \text { sq. } \mathrm{cm}
$$


Ex. (2) In $\triangle \mathrm{GHI}, 1(\mathrm{GH})=5 \mathrm{~cm}, 1(\mathrm{HI})=6 \mathrm{~cm}$ and $1(\mathrm{GI})=5 \mathrm{~cm}$. Find the area of $\triangle \mathrm{GHI}$.

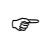

an isosceles triangle.

In $\triangle \mathrm{GHI}$ given alongside,

$1(\mathrm{GH})=5 \mathrm{~cm}$.

$1(\mathrm{HI})=6 \mathrm{~cm}$.

$1(\mathrm{GI})=5 \mathrm{~cm}$

Let,

$\mathrm{a}=5 \mathrm{~cm}$

Base, $b=6 \mathrm{~cm}$.

By using The New Formula of area of an isosceles triangle,

$\therefore$ Area of an isosceles $\triangle \mathrm{GHI}=\mathrm{b}$

$=\frac{4}{6} \times V$

4

The simplest fofm of $\begin{array}{rr}6 & \text { is } 3 \\ 4 & 2\end{array}$

$=3 \times(4 \times 25)-36$

$=\overline{3}^{2} \times \sqrt{100-36}$

$=\frac{2}{3} \times \sqrt{\phi 4}$

The square root of 64 is 8

$=3 \times 8=3 \times 8=24$

$-2 \quad 2-2$

$=12 \mathrm{sq} . \mathrm{cm}$.

$\therefore$ Area of an isosceles $\triangle \mathrm{GHI}=12 \mathrm{sq} . \mathrm{cm}$.

Verification :-

Here,

$1(\mathrm{GH})=\mathrm{a}=5 \mathrm{~cm}$.

$1(\mathrm{HI})=\mathrm{b}=6 \mathrm{~cm}$.

$1(\mathrm{GI})=\mathrm{c}=5 \mathrm{~cm}$.

By using the formula of Heron's

Perimeter of $\triangle \mathrm{GHI}=\mathrm{a}+\mathrm{b}+\mathrm{c}$

$$
=5+6+5
$$$$
=16 \mathrm{~cm}
$$

Semiperimeter of $\triangle \mathrm{GHI}$,

$$
\begin{aligned}
& \mathrm{S}=\frac{\mathrm{a}+\mathrm{b}+\mathrm{c}}{2} \\
& \mathrm{~S}=\frac{16}{2} \\
& \mathrm{~S}=8 \mathrm{~cm} .
\end{aligned}
$$

$\therefore$ Area of an isosceles $\triangle \mathrm{GHI}=$

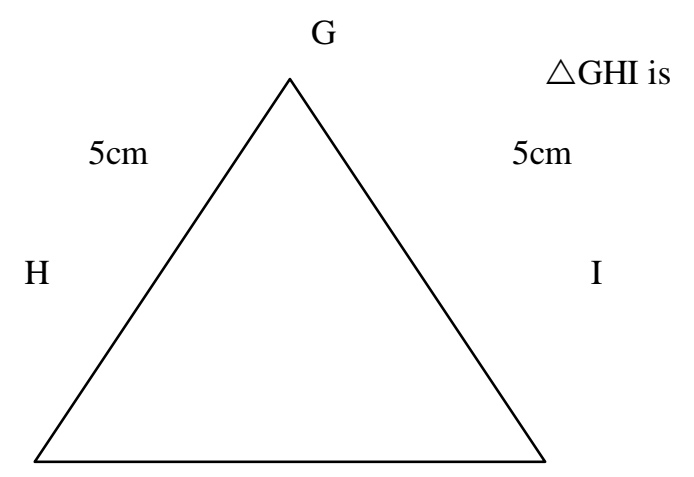




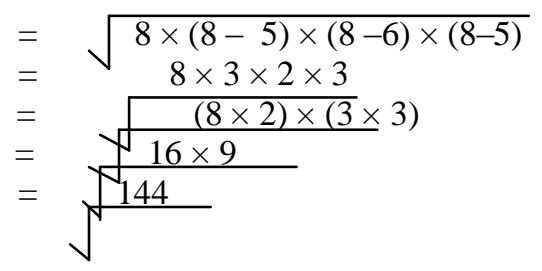

The square root of 144 is 12

$=12 \mathrm{sq} . \mathrm{cm}$

$\therefore$ Area of an isosceles $\triangle \mathrm{GHI}=12$ sq.cm.

\section{Explanation:-}

We observe the above solved examples and their verifications, it is seen that the values of solved examples by using the new formula of an isosceles triangle and the values of their verifications are equal.

Hence, The new formula of the area of an isosceles triangle is proved.

\section{Conclusions:-}

Area of an isosceles triangle $=$

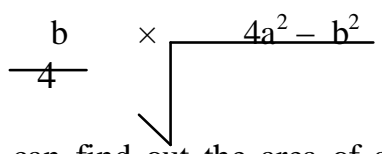

From the above new formula, we can find out the area of an isosceles triangle. This new formula is useful in educational curriculum, building and bridge construction and department of land records. This new formula is also useful to find the area of an isosceles triangular plots of lands, fields, farms, forests, etc. by drawing their maps.

\section{References:-}

